\title{
Why do GPs with a special interest in headache investigate headache presentations with neuroradiology and what do they find?
}

\author{
Steven Elliot • David Kernick
}

Received: 16 June 2011 / Accepted: 22 July 2011 / Published online: 29 September 2011

(C) The Author(s) 2011. This article is published with open access at Springerlink.com

\begin{abstract}
The general practitioner with a special interest in headache offers an important contribution to the management of headache in primary care where the majority of presentations take place. A number of guidelines have been developed for neuroradiological investigation of headache, but their clinical utility and relevance is not known. Fourteen general practitioners with a special interest in headache recorded consecutive headache consultations over a 3-month period, whether patients were investigated with neuroradiology and if so the reason for investigation and outcome. Reason for investigation was compared to the guidelines published for the use in primary care. 895 patients were seen, of whom $270(30.1 \%)$ were investigated. $47 \%$ of indications were outside the guidance framework used, the most common reason for investigation being reassurance. Of those investigated, $5.6 \%$ showed positive findings but only $1.9 \%$ of findings were felt to be of clinical significance. General practitioners with a special interest investigated with neuroradiology a greater level than general practitioners, but less than neurologists. However, yields of significant findings are broadly comparative across all groups. This report confirms other studies that suggest that even when there is a high level of clinical suspicion, yields of significant findings are very low.
\end{abstract}

Keywords Headache $\cdot$ Neuroradiology $\cdot$ Primary care

S. Elliot

Horizon Centre, 94 Littleton Road, Salford M7 3SE, UK

D. Kernick $(\bowtie)$

St Thomas Health Centre, Cowick Street, Exeter EX4 1HJ, UK

e-mail: su1838@eclipse.co.uk

\section{Background}

The majority of headache sufferers are reluctant to seek help and when they do, the condition is often poorly managed by the general practitioner (GP) [1]. In the UK, headache is the most common reason for a secondary care neurological referral but only a small number of neurologists have a special interest in the area and many referrals are inappropriate for a secondary care setting [2].

Reflecting these concerns, it has been suggested that clinics staffed by general practitioners with a special interest (GPwSI) working either in secondary care or in community headache clinics [intermediate care] should support GP colleagues who would continue to provide first-line headache care [3,4]. A GPwSI is a general practitioner who has developed enhanced skills so as to provide a variety of extended services that has traditionally been provided by secondary care specialists, and training and accreditation frameworks are available in a number of clinical areas including headache [5]. It has been suggested that a GPwSI headache service can satisfy patients with similar headache impact as those seen in secondary care at lower cost [6].

In the UK, the annual primary care consultation rate for headache is 4.4 per 100 patients of which $3 \%$ are referred to secondary care [7] where headache accounts for over $20 \%$ of new cases [8]. Although a brain tumour can present with a number of symptoms, headache is invariably a cause for concern for both patient and doctor. In the UK, the annual incidence of adult primary brain tumour of patients who present with headache is $0.01 \%$ of which $72 \%$ will present above the age of 50 [9] and when a patient presents to his/her GP with headache, the risk of a brain tumour is $0.09 \%$ [10].

Although a number of headache investigation guidelines have been developed [11-14], developing a rigorous 
evidence base remains problematic. The context in which the decision is made also plays an important part [15]. For example, in secondary care, patients often anticipate the exclusion of secondary pathology and consultants are under pressure to make a diagnosis at the first appointment. These factors result in a wide range of investigation patterns in secondary care with headache investigation rates of up to $60 \%$ [16].

Although a number of studies on radiological investigation have been reported from primary care GPs [17-20], there have been no reports from GPs with a special interest in headache. We are unaware of any studies that report the specific reason for imaging or compare these reasons with published guidelines. The aim of our study is to report the reasons GPwSI give for investigation of headache compared with published guidelines and to describe the findings of their investigations.

\section{Method}

14 GPwSIs, all members of the British Association for the Study of Headache (BASH) GPwSI group took part in the study. GPwSIs accepted referrals from their GP colleagues and worked either in a secondary or intermediate care setting. A record was kept of consecutive headache consultations over a 3-month period, whether they were investigated and if so the reason and outcome. Indications for investigation were compared against the BASH recommendations for primary care when brain tumour is suspected [14].

\section{Results}

895 patients were seen, of whom 270 (30.1\%) were investigated. Four GPwSIs worked in a secondary care, five in an intermediate care setting and two in a mixed setting ( 3 were not stated). $59 \%$ of the patients were investigated by MRI and the remainder by a CT scan. 15 (5.6\%) of investigated patients showed positive findings, a rate of $1.7 \%$ of all patients seen.

Table 1 shows the activity breakdown for each GPwSI and outcomes in terms of positive findings. Investigation rates of GPs varied between 12 and $60 \%$. However, only 5 cases $(1.9 \%)$ were felt to be of definite clinical significance to the headache presentation. Table 2 shows the indications for investigation within the framework defined by the BASH guidelines for primary care and positive findings. $47 \%$ of indications were outside the guidance framework. Table 3 expands the reasons other than indicated by the guidance framework that was used. The most common reason for investigation was for reassurance (41.7\%).
Table 1 Individual GPwSI activity

\begin{tabular}{lllll}
\hline GPwSI & $\begin{array}{l}\text { Number } \\
\text { consecutive } \\
\text { patients seen } \\
\text { in reporting } \\
\text { period }\end{array}$ & $\begin{array}{l}\text { Number } \\
\text { investigated } \\
(\%)\end{array}$ & $\begin{array}{l}\text { Number } \\
\text { positive } \\
\text { findings of } \\
\text { those } \\
\text { investigated } \\
(\%)\end{array}$ & $\begin{array}{l}\text { MRI/CT of } \\
\text { those } \\
\text { investigated } \\
(\%)\end{array}$ \\
\hline 1 & 25 & $5(20 \%)$ & 0 & $80 / 20$ \\
2 & 28 & $8(29 \%)$ & 0 & $63 / 37$ \\
3 & 43 & $26(60 \%)$ & $2(7.7 \%)$ & $18 / 82$ \\
4 & 29 & $13(44 \%)$ & $1(7.7 \%)$ & $62 / 38$ \\
5 & 57 & $19(33 \%)$ & $3(15.8 \%)$ & $95 / 5$ \\
6 & 59 & $18(30 \%)$ & $2(11.1 \%)$ & $28 / 72$ \\
7 & 64 & $25(39 \%)$ & 0 & $67 / 33$ \\
8 & 69 & $27(40 \%)$ & 0 & $100 / 0$ \\
9 & 71 & $10(14 \%)$ & 0 & $40 / 60$ \\
10 & 84 & $34(41 \%)$ & $2(5.9 \%)$ & $100 / 0$ \\
11 & 150 & $18(12 \%)$ & $4(22.2 \%)$ & $94 / 6$ \\
12 & 76 & $21(28 \%)$ & $1(4.8 \%)$ & $100 / 0$ \\
13 & 58 & $22(38 \%)$ & 0 & $0 / 100$ \\
14 & 82 & $23(28 \%)$ & 0 & $7 / 93$ \\
\hline
\end{tabular}

\section{Discussion}

We report on the rate and clinical findings of consecutive headache patients seen by 14 general practitioners with a special interest working across a number of settings. $30.16 \%$ of patients were investigated. This compares to rates of between 1.2 and $5.3 \%$, where GPs have direct access to neuroradiology investigation [14-18] and up to $60 \%$ rates reported to the neurologists [16].

There was a wide range in the number of patients investigated across the practitioners. This possibly reflects different local contexts that include access by GPs to neuroradiology and patient case mix. $15(5.6 \%)$ of the investigated patients showed positive findings, although of those only $5(1.9 \%)$ were felt to be of clinical significance. When GPs have access to investigation, significant abnormalities rates are reported between 2.4 and 1.4\% [21] and in secondary care when investigation is clinically selective the yield is $2.1 \%[16,22]$.

We found that the main reason for investigation was reassurance, an important indication reflected in other primary care studies $[15,23]$. However, the effects of investigations in terms of reducing anxiety in the longer term produce conflicting findings [24-26]. The identification of incidental pathology, its clinical relevance and the unnecessary anxiety it incurs is well recognised and can be important. We found that $3.7 \%$ of investigations showed abnormalities that were not clinically relevant. This compares with population studies of 2.7\% [27] and a recent GP study rate of $10 \%$ [17]. 
Table 2 Reason for investigation and findings (In some cases 2 or more reasons were listed) within the framework of BASH guidance for GPs when brain tumour is suspected

\begin{tabular}{|c|c|c|c|}
\hline $\begin{array}{l}\text { Indication for investigation within } \\
\text { BASH guidance for GPs }\end{array}$ & $\begin{array}{l}\text { Number of } \\
\text { indications for } \\
\text { investigation }(\%)\end{array}$ & $\begin{array}{l}\text { Number of positive } \\
\text { findings for each } \\
\text { indication }(\%)\end{array}$ & Positive findings \\
\hline 1. Papilledema & $1(0.3 \%)$ & $1(100 \%)$ & Idiopathic intracranial hypertension \\
\hline $\begin{array}{l}\text { 2. Significant alterations in memory, } \\
\text { confusion or co-ordination }\end{array}$ & $4(1.2 \%)$ & 0 & \\
\hline 3. New epileptic seizures & $2(0.6 \%)$ & 0 & \\
\hline 4. New onset cluster headache & $7(2.1 \%)$ & 0 & \\
\hline 5. Headache with a history of cancer elsewhere & $11(3.3 \%)$ & 0 & \\
\hline $\begin{array}{l}\text { 6. Headache with abnormal neurological signs or } \\
\text { relevant symptoms }\end{array}$ & $29(8.8 \%)$ & 0 & \\
\hline $\begin{array}{l}\text { 7. Headache aggravated by exertion or } \\
\text { Valsalva like manoeuvre }\end{array}$ & $27(8.2 \%)$ & $6(22.2 \%)$ & $\begin{array}{l}\text { Idiopathic intracranial hypertension, } \\
\text { subdural, chiari (x3), orbital abnormality }\end{array}$ \\
\hline 8. Headache associated with vomiting & $4(1.2 \%)$ & $1(25.0 \%)$ & Sinus thickening \\
\hline 9. Headaches that change significantly & $32(9.7 \%)$ & $2(6.3 \%)$ & Lesion temporal lobe, aneurysm \\
\hline 10. New headache in a patient over 50 years & $43(13.1)$ & 0 & \\
\hline 11. Headache that wake from sleep & $11(3.3 \%)$ & 0 & \\
\hline 12. Confusion & $2(0.6 \%)$ & 0 & \\
\hline 13. Other reason outside of guidance (See Table 3) & $156(47.4 \%)$ & $6(3.8 \%)$ & (See Table 3) \\
\hline
\end{tabular}

Table 3 Reason for investigation outside of guidance framework and findings

\begin{tabular}{lcl}
\hline $\begin{array}{l}\text { Reason for investigation outside } \\
\text { of BASH guidance for GPs }\end{array}$ & $\begin{array}{l}\text { Number } \\
\text { investigated }(\%)\end{array}$ & Positive findings \\
\hline Reassurance & $65(41.7 \%)$ & 0 \\
Atypical headache & $21(13.5 \%)$ & 0 \\
Prolonged or complex aura & $14(9.0 \%)$ & 0 \\
Headache on exertion & $7(4.5 \%)$ & 0 \\
Orgasmic headache & $1(0.6 \%)$ & 0 \\
Unilateral tinnitus & $5(3.2 \%)$ & 0 \\
Cough/valsalva induced headache & $6(3.8 \%)$ & 0 \\
Thunderclap headache & $4(2.7 \%)$ & 0 \\
New daily persistent headache & $10(6.4 \%)$ & 0 \\
Other (not stated) & $23(14.7 \%)$ & 6 \\
& & Multiple emboli, infarct [2], aneurysm, \\
\end{tabular}

We conclude that GPs with a special interest in headache investigate at a level that is above GPs, but lower than neurologists whereas yields of significant findings are broadly comparative across all groups. We report that reassurance is the most common cause for investigation. This is difficult to justify on clinical grounds, particularly against a background of limited health care resources and a very low rate of significant findings where there is no clinical suspicion. Direct discussion of patient concerns and the implications of neuroradiological investigation may be more likely to reassure patients than unnecessary tests.

With attempts by many health systems to reduce referral rates to secondary care, access by GPs to neuroradiology is likely to increase. In an area of low yield, our findings may be able to inform revision of guidance on investigation in primary care when patients present with headache.

Acknowledgments We thank the members of the Primary Care Group of the British Association for the Study of Headache for taking part in this study.

\section{Conflict of Interest None.}

Open Access This article is distributed under the terms of the Creative Commons Attribution License which permits any use, distribution and reproduction in any medium, provided the original author(s) and source are credited. 


\section{References}

1. Forward SP, McGrath PJ, McKinnon D, Brown T, Swann J, Currie EJ (1998) Medication patterns of recurrent headache sufferers: a community study. Cephalalgia 18:146-151

2. Sender J, Bradford S, Watson D, Lipscombe S, Reece T, Manley R, Dowson A (2004) Setting up a specialist headache clinic in primary care: general practitioners with a special interest in headache. Headache Care 1:165-171

3. Dowson A, Lipscombe S, Sender J, Rees T, Watson D, MIPCA Migraine Guidelines Development Group. Migraine in primary care advisors (2002) New guidelines for the management of migraine in primary care. Curr Med Res Opin 18:414-439

4. (2001) Recommendations for the organisation of headache services. British Association for the Study of Headache, London

5. Implementing a scheme for general practitioners with a special interest. Department of Health/Royal College of General Practitioners. http://www.gencat.cat/ics/professionals/recull/bibliografic/ 2007_3/Implementing.pdf. Accessed April 2002

6. Ridsdale L, Doherty J, McCrone P (2008) A new GP with a special interest headache service. Br J Gen Pract 58:478-483

7. Latinovic R, Gulliford M, Ridsdale L (2006) Headache and migraine in primary care: consultation, prescription and referral rates in a large population. J Neurol Neurosurg Psychiatry $77: 385-387$

8. Bekkelund S, Albretsen C (2002) Valuation of referrals from a general practice to a neurology department. Fam Pract 19: 287-289

9. (1998) Office for National Statistics, Series MBI No 25, London

10. Kernick D, Hamilton W (2007) Clinical features of primary brain tumours: a case controlled study using primary care records. Br J Gen Pract 57:695-699

11. Sandrini G, Friberg L et al (2004) Neurophysiological tests and neuroimaging procedures in non-acute headache: guidelines and recommendations. Eur J Neurol 11:217-224

12. (2011) Referral Guidelines for suspected cancer (Brain tumour). National Institute of Clinical Effectiveness, London. http://www.nice. org.uk/nicemedia/live/10968/29816/29816pdf. Accessed September 2011

13. Referral Guidelines for suspected cancer. National Institute of Clinical Effectiveness. http://www.nice.org.uk/pdf/cg0274guide line.pdf. Accessed November 2005
14. Kernick D, Ahmed F, Bahra A et al (2008) Imaging patients with suspected brain tumor. Guidance for primary care. Br J Gen Pract 58:880-885

15. Morgan M, Jenkins L, Ridsdale L (2007) Patient pressure for referral for headache: a qualitative study of GPs' referral behaviour. Br J Gen Pract 57:29-35

16. Clarke C, Edwards J, Nicholl D, Sivaguru A (2010) Imaging results of the consecutive series of 530 new patients in the Birmingham headache service. J Neurol 257:1274-1278

17. Thomas R, Cook A, Main G, Taylor T, Caruana E, Swingler R (2010) Primary care access to computed tomography for chronic headache. Br J Gen Pract 60:426-430

18. Becker L, Iverson D, Reed F, Calonge N, Miller R, Freeman W (1988) Patients with new headache in primary care: a report from the ASPN. J Fam Pract 27:421-427

19. Becker I, Green L, Beaufait D, Kirk J, Froom J (1993) Use of CT scans for investigation of headache: a report from ASPN. J Fam Pract 37:126-127

20. Couchman G, Forjuoh S, Rajab M, Phillips C, Yu J (2004) Nonclinical factors associated with primary care physicians ordering patterns of magnetic resonance imaging/computed tomography for headache. Acad Radiol 11:735-740

21. Benamore R, Wright $\mathrm{D}$, Britton I (2005) Is primary care access to CT brain examinations effective? Clin Radiol 60:1083-1089

22. Tsushima Y, Endo K (2005) MR imaging in the evaluation of chronic or recurrent headache. Radiology 235:575-579

23. Ridsdale L, Clark L, Dowson A et al (2007) How to patients referred to neurologists for headache differ to those managed in primary care? Br J Gen Pract 57:388-395

24. Fitzpatrick R, Hopkins A, Harvard-Watts O (1983) Social dimensions of healing: a longitudinal study of outcomes of medical management of headaches. Soc Sci Med 17:501-510

25. Howard L, Wessely S et al (2005) Are investigations anxiolitic or anxiogenic? A randomised controlled trial of neuroimaging to provide reassurance in chronic daily headache. J Neurol Neurosurg Psychiatry 76:1558-1564

26. Fitzpatrick R, Hopkins A (1981) Referrals to neurologists for headaches not due to structural disease. J Neurol Neurosurg Psychiatry 44:1061-1067

27. Morris Z, Whiteley W et al (2009) Incidental findings on brain magnetic resonance imaging: systematic review of meta analysis. BMJ 339:547-550 